\title{
The relationship between irrigation-induced electrical loads and antecedent weather conditions in Tasmania, Australia
}

\section{Tom Latham ${ }^{1}$}

Christopher J. White ${ }^{1,2,3}$

Tomas A. Remenyi ${ }^{2}$

${ }^{1}$ School of Engineering, University of Tasmania, Hobart, Australia

${ }^{2}$ Antarctic Climate and Ecosystems Cooperative Research Centre (ACE CRC), Hobart, Australia

${ }^{3}$ Department of Civil and Environmental Engineering, University of Strathclyde, Glasgow, UK

For submission to Irrigation Science

\section{Corresponding author}

Dr Christopher J. White

Postal address: School of Engineering, University of Tasmania, Private Bag 65, Hobart, TAS, 7001, Australia

Telephone number: +61 (0) 362267640

Email address: chris.white@utas.edu.au 


\section{Abstract}

Over the past decade in Australia, there has been a general trend towards the introduction of electrical motors to operate irrigation pumps. While electrical motors provide many advantages over the alternatives, electrical loads can aggregate in some areas to become large peaks, which challenge the existing electrical distribution networks. This is especially true during extreme hot or dry periods, when irrigators collectively demand significant electrical resources at the same time. While there is an inherent link between weather conditions and the amount of electricity used for irrigation, this relationship is poorly understood. Previous studies have either focused on localised data related to concurrent temperature, rainfall and soil moisture, or they have annualised summaries over large areas. In this study, we compare intensive irrigation periods with the Drought Factor at a case study irrigation scheme in Tasmania, Australia, finding a strong relationship between electrical load and periods when the Drought Factor is $>6$. This relatively simple relationship may be useful for managers of electricity supply and distribution, managers of water resources, and irrigators, as it may be used to minimise the risk of exceeding the capacity of the electricity network, improve water availability and optimise irrigation scheduling.

\section{Keywords}

irrigation; weather; climate variability; electrical load; power; soil moisture; drought factor 


\section{Introduction}

Irrigation has become essential for global food production in a warming and more uncertain climate (Evans et al. 1996; Döll 2002; AgInnovators 2013). All aspects of irrigation, including water resources, energy demands and consequential impacts, must be understood in the context of climate change for future food security (Schiermeier 2015; FAO 2017). While $20 \%$ of the world's cultivated lands are irrigated, this fraction disproportionately produces $40 \%$ of the world's total food product (Bos et al. 2009) The increasing demand and price for energy affects all economic sectors, including irrigated agriculture (Fernández García et al. 2016), therefore understanding how water resources are used now and how water demand can be met efficiently and inexpensively in a changing climate will be essential for long-term sustainable water usage around the world (Gleick 2003; Garcia-Tejero et al. 2011; Peck et al. 2013). The complex interaction between energy production, water demand for irrigation and the weather conditions that determine water and energy usage is, therefore, of increasing interest, given existing climate uncertainty and the prediction of more extreme weather events, such as heatwaves and drought (Döll 2002; Alfaro et al. 2005; Stocker et al. 2013; Doulgeris 2015; Bartos and Chester 2015).

Across the energy sector consumption fluctuates markedly according to prevailing weather conditions, irrigation is no exception and suppliers of energy are highly dependent upon weather and climate forecasts (Dubus 2010). Water distribution, via pumping, for irrigated agriculture is a primary user of energy and is often associated with high electrical load through the extensive use of electrical motors on irrigation pumps (Evans et al. 1996; AgInnovators 2013). This 'irrigation-induced load', hereafter referred to as irrigation load, is the electrical load that arises in locations or regions dominated by irrigated agriculture. Irrigation schedules are typically 
dictated by environmental factors, economic constraints, social norms, infrastructure, workforce availability and other factors. Of these, the environmental factors (weather) and economic constraints (power tariffs) can be relatively constant across large areas despite the different cropping patterns and plant phenology factors, resulting in most farmers irrigating at more or less the same time (Gellings 2009). The concentration of irrigation scheduling and coincident use of electrical irrigation pumps causes large sustained load increases on the electrical distribution network (Evans et al. 1996). Since at least the 1970s, researchers in the USA have been investigating the effect of irrigation on peak loading (Stetson and Addink 1977). Stark and Stetson (1985) found that between 1970 and 1985, the irrigated area in central Nebraska had expanded four-fold, and that electrical motors for pumps increased loading by as much as seven times the average. In Tasmania, the added strain of irrigation load at peak times can occasionally exceed the capacity of the electricity network (Chong Ong, pers. comm., April 2016).

As weather determines not only when to irrigate, but also water availability, there is an inherent - but often unquantified - relationship between irrigation and antecedent weather conditions, including extreme events. Leenhardt et al. (2004a), for example, note that current water management procedures often fail in years with extreme weather and hydrological conditions. Improving the understanding of how irrigation and weather events are related would, therefore, enable electricity networks to be tailored to cope with peak irrigation demands and support improved decision-making ahead of forecasted weather events, both now and in future climates. Several studies have developed irrigation scheduling models based on climatic data or correlated weather-to-water use (e.g. Guerra et al. 2005; Georgiou 2008; Doulgeris et al. 2015), however only a few studies have directly investigated the effect of weather on irrigation loading. Stark 
and Stetson (1985) analysed the relationships between irrigation load, rainfall and temperature using data collected directly from metered irrigation pumps and a residential feeder. They found irrigation load was only vaguely related to maximum temperature, but it was significantly related to the length of time since the last watering (from rainfall or irrigation). Alfaro et al. (2005) used soil moisture for encapsulating 'weather' into an irrigation-tailored variable. They did not have access to data from isolated pumps as Stark and Stetson (1985) did. Instead, they used data from areas where the electrical load was primarily influenced by irrigation, finding a strong annual correlation (although this conclusion was limited by the restriction of the analysis to annual summaries of irrigation load and weather). More recently, Leenhardt et al. (2004a) presented a simulation platform aimed at improving decision-making in water management, which Leenhardt et al. (2004b) validated using water consumption and electricity usage data during the irrigation season in south-western France. Although the study used only two years of data, Leenhardt et al. (2004b) noted that improved weather-influenced rules for starting and/or delaying irrigation (i.e. following rainfall) could improve decision-making, highlighting the potential benefits of understanding the fundamental relationship between irrigation and weather.

Irrigation has been part of the Australian farmer's 'toolkit' for more than 100 years (Irrigation Australia 2017). Initially, simple technology such as flood irrigation was used, which was followed by direct application systems utilising diesel-driven pumps. At present, there is a transition away from using diesel pumps to electrical pumps (Shorten et al. 2014). Despite this trend, there have been no studies in Australia investigating the relationship between irrigation loads and antecedent weather (Shorten et al. 2014). Australia is the driest inhabited continent in the world, with irrigation in many areas so critical to farming that agriculture consumes $50-70 \%$ 
of Australia's water resources (Roth 2012; NPSI 2012). In Australia's south-eastern island state of Tasmania, a state-wide irrigation network - mostly driven by pumps with electrical motors — has been under development since 2007 with significant uptake from farmers. Tasmania constitutes only $1 \%$ of Australia's land mass, yet receives $13 \%$ of Australia's total rainfall (Tasmanian Institute of Agriculture 2017). While rainfall is relatively abundant in some parts of the state, other regions have experienced reduced rainfall over the last decade, and future projections suggest that this trend could continue (Grose et al. 2010). The redistribution of water from wet to dry areas has become a political imperative as well as a practical one. In 2009 , the CSIRO established that a state-wide irrigation network would improve agricultural production and ensure food (and economic) security for the state (CSIRO 2009). Since the publication of this report, Tasmania's irrigation network has grown rapidly, with increasing load being placed on the state's electrical distribution network during the irrigation season (October through to March). In the worst cases this increased load can cause local supply interruptions. Energy security is a major priority of the state's electricity-distribution utility, TasNetworks (Chong Ong, pers. comm., April 2016). A deeper understanding of the relationship between irrigation load and antecedent weather conditions would, therefore, benefit the managers of electricity distribution, giving them the ability to maximise network capability during peak irrigation periods. Strategies include avoiding planned maintenance activities that impact the capacity of the network, additional investment to strengthen the network, and tariff incentives for farmers to avoid irrigation at times coincident with electricity usage during the irrigation season (TasNetworks 2015). It would also help irrigation managers decide when and where water should be stored, and assist irrigators in optimising the efficiency of the water they buy (Mike O’Shea, pers. comm., 12 April 2016). 
In this study, we explore the relationship between irrigation loading and weather conditions in Tasmania. Following the findings of previous studies (Stetson and Addink 1977; Stark and Stetson 1985; Alfaro et al. 2005), the focus of this study was on antecedent weather conditions, although concurrent conditions were also considered. Through consultation with experts and industry, we focus on a representative pilot study involving a single irrigation scheme and the load it places on a single power feeder, before discussing the applicability of our methods across the entire state.

\section{Methods and data}

The Greater Meander Irrigation Scheme (GMIS) is centred on the township of Deloraine in the central north of the state (Figure 1). It experiences a cool, temperate climate and is one of the largest irrigation schemes in Tasmania, providing $36 \mathrm{GL}$ of water to a $190-\mathrm{km}^{2}$ region, primarily for dairy cows, beef, vegetables, hay and potatoes. The GMIS was selected as the case study because of four highly favourable features: it is a large agricultural region representative of other irrigation schemes; the irrigation load is high relative to residential and/or commercial loads; the power supply to $80 \mathrm{~km}^{2}$ (a significant proportion of the region) can be isolated to a single feeder; and historical weather? records are greater than 10 years, providing enough inter-annual variability to include wet and dry years. Large-scale irrigation in the GMIS has been undertaken since 2007 when the Meander Dam was completed. Since then, irrigation expansion has resulted in a $76 \%$ rise in financially-stable irrigation of high-quality land (Meander Valley Council 2013). The period from 2010 to 2013 saw agricultural production in the region increase by $\$ 40$ million ( $\sim 60 \%$ ) to $\$ 102$ million, representing $10.4 \%$ of Tasmania's gross agricultural product 
that year (Meander Valley Council 2013). The increase in agricultural production, and the subsequent economic success, of the region can be directly attributed to the success of the expanded GMIS (Meander Valley Council 2013).

\section{TasNetworks electrical load data analysis}

In Tasmania, high-voltage transmission lines split into $22-\mathrm{kV}$ lines, called feeders, that provide power to a sub-region of the network. The feeder out of the Railton substation is the single source of electrical power for a significant portion of the GMIS. At the time of our study it had 13 years of uninterrupted data at half-hour temporal resolution, from which the irrigation load could be isolated. Initially, underlying trends in the data were assessed on an inter-annual, monthly, and daily basis. Data were split by day-of-week and grouped by month, before means and quantiles (5th and 95th) were calculated. Splitting the data in this manner retained a constant frame of reference from year-to-year and allowed the easy distinction between weekly patterns compared to the longer seasonal cycle. No significant day-of-week trends were observed, so all weekdays could be considered equal.

Consultation with irrigators and industry experts found that it is common practice for farmers to schedule irrigation during low tariff periods (primarily $10 \mathrm{pm}$ to $6 \mathrm{am}$ ) to reduce costs. This practice is generally adhered to despite the complications of plant phenology, equipment and workforce limitations. Similar behaviour has been noted around the world (Addink and Addink 2003). This provided a convenient daily window within which to identify 'irrigation days' versus 'non-irrigation days' in the load data. The mean electrical load was calculated within the low tariff period to construct a daily time series of irrigation load (4487 days of data). This not only 
reduced noise in the signal, but also transformed the raw electrical load data into a useful form that could be aligned with the Bureau of Meteorology (BoM) observational datasets.

\section{Weather data}

The daily maximum temperature and total rainfall data used in this study were extracted from the BoM's online climate data portal (BoM 2017). These time series of observations are generated by a network of recording stations across Australia and are freely accessible. Daily regional mean values for maximum temperature were calculated for the five stations nearest the TasNetworks distribution area that had complete data: Liawenee (station number 096033), Launceston Rifle Range (091050), Launceston Airport (091311), Sheffield School Farm (091291) and Launceston Ti Tree Bend (091237). Rainfall data were obtained from the Meander station (091061). The regional mean data and the rainfall data provided a daily time series which could be compared to the irrigation load data.

In addition to maximum temperature and total rainfall, the Soil Dryness Index (SDI) and the Drought Factor (DF) indices were used. The SDI is a soil moisture balance, describing the amount of rainfall required to bring the soil moisture to field capacity (Mount 1972) and is a simplified version of the soil moisture balance described by Allen (1998). This SDI is calculated from rainfall, evapotranspiration (ET), runoff and a number of stationary inputs, including ground cover (Finkele et al. 2005). The DF, by way of comparison, is an index primarily designed for use in calculating the risk of bushfire (Finkele et al. 2005). The DF design is based on the concept of wetting from above and wetting from below, accounting for both rainfall and stored soil moisture. It uses the SDI in conjunction with a rainfall algorithm to estimate wetness 
from above (rain) and below (soil). While many revisions of the DF index exist, the BoM uses the method outlined by Griffiths (1999) with a retrospectively-added limiting function described by Finkele et al. (2005 rev 2006). The DF has been designed such that a value of five represents conditions where $50 \%$ of fuels are available for burning, a value of two represents $20 \%$ and so on. Although the intended purpose is different to the SDI, the DF index captures the overall influence of various weather variables suited to this study on antecedent conditions, and this index is available at several locations near the study region, as well as on an interpolated grid covering southern Australia (Finkele et.al. 2006). Daily SDI and DF data for the Meander station were provided directly by the BoM.

\section{Analyses}

The irrigation load was compared to each of the daily values for temperature, rainfall and SDI. To determine if there was a temporal offset or function to these relationships, both offsets and running means were investigated. Offsets of 1 and 2 days backward (i.e. irrigators responding to weather forecasts) and forward (i.e. responding to conditions experienced) were investigated. Running means were also considered using windows of 3, 5 and 10 days, centred on the day in question (i.e. considering reactions to forecast weather) and left aligned (i.e. only considering antecedent conditions). As the DF index is already a significant transformation of climatic and biological influences, no further irrigation specific adjustments were made before conducting the analysis against irrigation load

These comparisons, assessed using linear regression, were separated into month-of-year groups? to determine if seasonal factors could be influential to the relationship. It was also decided that 
instead of considering calendar years it would be more practical to consider a year as running from July to June, referred to hereafter as a growing year. In doing this, each irrigation season (October through March) was contained in a single twelve-month period. From the linear regressions conducted, no relationships were found with either temperature or rainfall. However, the daily SDI and DF both presented notable relationships. Closer inspection of the SDI and DF regressions revealed that while irrigation load was related to SDI on an annual scale, it was more closely related to DF on a daily scale. It was, therefore, decided that the variable best suited to further analysis was the DF, and the remaining analysis used techniques based on the DF.

From the regression analysis a relationship between irrigation load and the DF is observable when DF $>6$. To confirm this threshold, at DF 6 a Generalized Additive Model (GAM) was fitted to the regression (Wood 2011). GAMs use smooth functions as predictors in the same manner that ordinary linear regressions use variables (Wood 2006). Smooth function predictors can take a great many forms and as a result can fit a wide range of curves to data. The threshold at DF 6 was truly independent of year, or month-of-year. T-tests further supported this threshold, so linear regressions were conducted to either side of this point.

\section{Analytical tools}

Data was analysed using the $\mathrm{R}$ programming language ( $\mathrm{R}$ Team 2017), using base packages and the following tools: RStudio (RStudio Team 2015), readxl (Wickham 2016), caTools (Tuszynski 2014), miscTools (Tuszynski 2014; Henningsen and Toomet 2013), dplyr (Wickham and Francois 2016), $m g c v$ (Wood 2011) and lubridate (Grolemund and Wickham 2011). All statistical methods used the default parameter values. 


\section{Results}

Figure 2 shows the time series used in the analysis. Maximum temperature (Figure 2f) follows an approximately sinusoidal pattern, ranging from 5 to 38 degrees Celsius (in the Austral winter and summer, respectively), whereas rainfall (Fig. 2e) is less cyclical, with high inter-annual climate variability. Typical annual rainfall for the region is between 600 and $1100 \mathrm{~mm} /$ year (BoM 2017). This is relatively evenly spread across all months, although on average there is slightly higher rainfall during the winter months and less during the summer. The SDI (Fig. 2d) follows a seasonal pattern, ranging from 0 to 150 . During most winters, the SDI is consistently low, and rises gradually, increasing to a peak during summer before decreasing rapidly during autumn towards 'winter-like' conditions. Winter SDI values are $\sim 10(+/-10)$, with limited inter-annual variability. Summer values are generally $\sim 50(+/-30)$, with significant inter-annual variability where in the driest years values remain $>100$ for weeks. Aside from the rapid post-summer drops, the SDI changes gradually, with high maximum temperatures and low rainfall corresponding to high SDI values, and vice versa. As the DF is a function of the SDI, it follows a similar seasonal cycle, ranging from 0 to 6 in winter and 0 to 10 in summer. Values of 10 are rare, only achieved during the most prolonged periods of low rainfall. The DF algorithm results in an increasing exponential decay curve (i.e. the DF increases rapidly post rainfall, and the daily increase decays to an asymptote with each subsequent day of no rain). This is followed by abrupt decreases towards zero following rainfall days. Figures 4 and 2 shows there to be evidence of some congestion when DF approaches 6; the reasons for this are investigated and discussed below. 
The 'total electrical load' profile and irrigation load profile (Figures $2 \mathrm{a}$ and $2 \mathrm{~b}$ respectively) both follow seasonal patterns - low in winter, high in summer - again with significant inter-annual variability in summer. Prior to 2007, the cyclic summer maxima are much less pronounced, corresponding to less irrigation load prior to large-scale irrigation. After the completion of the Meander Dam in 2007, the summer maxima become more pronounced but vary in shape and magnitude between irrigation seasons.

Importantly, high maximum temperatures and low rainfalls correspond to high SDI and DF values which, in turn, correspond to high irrigation load. A comparison of two very different years, 2011 and 2013 (shaded grey in Figure 2), illustrates the relationship. Conditions within 2011 were cooler and wetter, corresponding to lower than average SDI, DF and irrigation load values. Conversely, the 2013 growing season was much hotter and much drier, corresponding to very high SDI, DF and irrigation values. Therefore, on a seasonal scale a relationship between weather and electrical load clearly exists and was strengthened following the introduction of large-scale irrigation to the Meander Valley in 2007.

Regression analysis with the SDI reveals strong relationships during the irrigation season (e.g. a maximum R-squared of 0.78 in November, Figure 3). Despite the evident relationships during the irrigation season (October to March), there is a tendency for each year-month pair to be grouped as they rely solely on the previous day's SDI, temperature maximum and rainfall. This limits the predictive capacity of the SDI within any one growing year. Collectively, however, the SDI shows a strong relationship to irrigation load but provides limited use in a daily predictive capacity. Regression analysis with DF values reveal weaker overall relationships (e.g. a 
maximum of 0.61 in January) but with values expressed over a broad range within any yearmonth pair (Figure 4). The broad spread of the values taken by the DF in each year-month pair provides far more predictive capacity than the SDI (Figure 3) which tends to cluster. The relationship is still quite weak, but there is an apparent change in the nature of the relationship when DF $>6$. The DF 6 threshold exists independently of year or month and separates the data distinctly.

A monthly inter-annual comparison of the data in the DF provides more practical information than the SDI, inferring that the additional antecedent information captures more of the contributing factors that influence irrigation scheduling. Figure 4 shows a distinct change in the relationship between irrigation load and the DF either side of DF 6, especially in October, November and December. This change in behaviour at DF 6 is apparent through to March, although it becomes less defined. Interestingly, the change in relationship occurs at, or close to, a DF value of 6 , the point where the DF behaviour is seen to change. Thus, for DF $<6$, the DF changes rapidly day-to-day; for $\mathrm{DF}>6$, the DF values increase gradually, whilst decaying exponentially (Figure 2c). This was further tested with GAM fits, which yielded a remarkably consistent threshold at (or near) DF 6, even within the non-irrigation season months (Figure 5). The GAM fits take into account inter-annual variability and identifies if there is a standard response across all seasons. The relationship is clearest in the period from August to November (the pre-irrigation and early irrigation season), but is observed in all months except March and April. To ensure this was not an artefact of the DF index, we investigated further. While developing the DF algorithm, BoM observed that during prolonged dry periods the DF increased too quickly post rainfall, requiring a limiting function as an amelioration. The side-effect of this 
function is that where $0<\mathrm{SDI}<20$, DF values are limited to a maximum of $\sim 6.1$ (Finkele et al. $2005 \mathrm{rev}$ 2006). This results in a tendency for DF values of 6.1 to be over-represented, occurring twice as often as any other value, but it is inconsequential to this study. This is most obvious in the June, July and August panels of Figure 4, but can also be seen in Figure 6 . Therefore, DF $<5$ indicates moist soil conditions, $5<\mathrm{DF}<7$ indicates neutral conditions, and DF $>7$ indicates dry soil conditions, supporting the potential use of the DF $>6$ threshold as an indicator of the need to irrigate.

Splitting the data into two groups of DF $<6$ and DF $>6$ highlights two sub-clusters of data: preGMIS (2003 to 2006, browns and oranges in Figure 6) and post-GMIS (2008 to 2015, greens and blues in Figure 6). Where $\mathrm{DF}<6$, irrigation load values are assumed to generally represent electrical base load, and there is a distinct clustering where pre-GMIS base loads are generally higher with more inter-annual variability than post-GMIS base loads. While interesting, this is not of relevance to this study. Where DF $>6$, the pre-GMIS irrigation loads are far lower (more similar to DF < 6 values) with a weaker relationship to the DF. In 2007 (coloured red in Figure 6), the GMIS was implemented and this is reflected in the data, with 2007 exhibiting properties midway between pre-GMIS and post-GMIS clusters and representing a transition point between the two regimes. Post-GMIS irrigation loads where DF $>6$ are significantly greater than those where $\mathrm{DF}<6$, with a strong relationship to the DF in all post-GMIS growing years (reflected in the steeper slope of the linear regression), even during wet growing years (e.g. 2010). PostGMIS, the average relationship is robust with limited inter-annual variability: for each DF unit there is about $650 \mathrm{~kW}(+/-130 \mathrm{~kW})$ of additional irrigation load. This linear model yields an Rsquared value of 0.49 for the entire irrigation season, and a value of 0.71 if only the months of 
October to January are considered. This early-season strength is expected due to the decoupling of the DF and irrigation load with the progression of the season.

\section{Discussion}

The analysis of the electrical-load profile and the low-tariff irrigation window highlights the existence of trends in the GMIS case study of higher overall power usage throughout summer (because of irrigation and air conditioning) and lower average loads throughout the remainder of the year. In the irrigation window of $10 \mathrm{pm}$ to $6 \mathrm{am}$, there is evidence of large fluctuating loads. Although there are minor weekday/weekend differences, weekend median loads are generally lower and slightly later in the day, but they are primarily outside of the intensive irrigation period. Accordingly, all days of the week are considered equal. Both median load (based on dayof-week-of-month) and load range in the intensive irrigation hours are significantly larger in the irrigation season, particularly in January and February. These observations confirm the preference to irrigate between $10 \mathrm{pm}$ and 6 am and the tendency for increased irrigation in the height of the irrigation season. Undoubtedly this method of isolating irrigation load is simplistic; a more rigorous processing of the signal — to identify irrigation usage outside of this irrigation window - may alter the results slightly, but for the purposes of this case study the method used is deemed sufficient.

Alfaro et al. (2005) and Stark and Stetson (1985) found relationships between irrigation load and rainfall and temperature, but on annual timescales as opposed to daily timescales. The same relationship was found in this study, with irrigation load being higher in dry, hot years, and lower in cool, wet years. However, daily-scale relationships with rainfall and temperature in isolation 
were absent, with all R-squared values below 0.1 . This is perhaps not surprising as the amount of water available to a crop is not directly related to any single component of weather, but is a function of antecedent conditions and local factors. As such, the climate indices - which incorporate the effects of many climatic and other factors - proved more suitable. The SDI is a simplistic soil moisture balance between rainfall, runoff and evapotranspiration. The SDI includes broad, static ground-cover factors (7 types) and a linear evapotranspiration model based on average monthly maximum temperature and pan evaporation for Australian capital cities (Finkele et al. 2005 rev 2006). Understandably, this approach to evapotranspiration and the limited range of ground covers make it more suited for larger-scale applications rather than the crop-by-crop approach adopted by Allen (1998). In comparison, the DF was designed to predict bushfire and estimates fuel availability rather than soil moisture. Thus, it weighs antecedent conditions and incorporates all the climatic and bioclimatic inputs through the SDI. Although the DF is not related to irrigation, Stark and Stetson (1985) suggest that the time since last rainfall is fundamental to understanding the irrigation/weather relationship. Such antecedent conditions are accounted for in the DF index, which supports its consideration in this study.

Figure 7 demonstrates the load variability around DF 6, and the possible influence of weather forecasts influencing irrigation decision-making. In 2011, the DF was consistently reaching 6; however, regular (presumably forecasted) rainfall meant that irrigation was not used (irrigation load was consistently low). On the other hand, in 2015 the DF reached 6 in early October and remained generally above 6 until the end of January. Very few rainfall events were observed during this period, resulting in a sustained and high irrigation load. Across all seasons, there are a number of coincident dips in irrigation load and the DF, most of which occur at times of 
significant rainfall. Figure 7 therefore highlights two key points: each year the maximum irrigation load is associated with the max DF, and larger observed rainfalls of $9+\mathrm{mm}$ per day (which regularly coincide with abrupt decreases in irrigation load) are required to dramatically drop the DF.

From October through to January, both the SDI and DF are quite strongly related to irrigation load in the GMIS. The strength of this relationship decreases later in the irrigation season (February and March). A fundamental limitation of using the SDI and DF data is that water in the models is purely climatic (i.e. there is no account of the water added from irrigation); therefore as soon as farmers begin to irrigate, the model breaks down. As the season progresses, this effect is amplified. Weather conditions may also give way to a multitude of other factors in terms of importance, including infrastructure limitations, crop requirements, prematurely exhausted irrigation rights, irrigation without regard of weather, or the fact that some crops are already harvested by this time. As such, irrigation usage reduces and the subsequent irrigation load becomes decoupled from the antecedent weather conditions.

Regardless of the late-season behaviour, the established threshold at DF 6 and the strength of the relationship up to and including January in the GMIS, provides valuable information to irrigation service providers who can conclude that if the DF is below 6, the likelihood of irrigation is low. If the DF is consistently close to 6 however, they can expect some irrigation, and if DF is well above 6, they can expect intense irrigation. Using this 'rule-of-thumb', electricity-distribution utilities may improve their capacity to predict and potentially avoid system overloads on short timescales, and better schedule unavoidable system maintenance and upgrades during the 
irrigation season on longer timescales. Similarly, irrigation service providers will have a better idea of when, where and for how long water resources will be needed, which may assist with the logistics of water resource distribution.

There is the potential to tailor the DF index into an irrigation-specific index by incorporating a more complex ET model into the SDI, using an approach similar to that set out by Allen (1998), or by incorporating the BoM's more sophisticated ET evapotranspiration dataset. In this way, nuances of soil and crop types could be accounted for, along with extra climatic variables such as solar radiation and wind. The incorporation of human influences such as irrigation volumes would also be a major step forward, however this would have to be undertaken on a paddock scale.

This study has shown that there is a measurable and predictable relationship between irrigation load and antecedent weather conditions within the GMIS. Given the relative stability of the DF index (i.e. primarily that a DF of 6 represents 'neutral' soil moisture, one neither particularly wet or dry), it is reasonable to assume that the threshold of 6 will remain constant across Tasmania, although this is yet to be tested and validated. Further work is needed to expand the scope of this study to include all irrigated regions of Tasmania, followed by the inclusion of other national irrigation schemes. The methods described in this article show great promise, but there is room for further work, such as identifying irrigation events in electrical load data, or incorporating smaller scale or crop-specific components into the antecedent weather index. Similarly, to understand what drives the scheduling of irrigation, it would be useful to investigate the behavioural responses of irrigators to antecedent conditions and weather forecasts. Establishing 
the amount of rainfall required to prevent irrigation, and subsequently how long the effect will last, would be a valuable tool for irrigators, and for water and electricity providers.

\section{Conclusions}

In this study, the Greater Meander Irrigation Scheme case study provided several significant findings with regard to the relationship between irrigation load and antecedent weather conditions in Tasmania. Irrigation load was identified in the load profile from 10 pm to 6 pm, the period with the lowest electrical power tariff, with relationships identified between irrigation load and both the SDI and DF. The relationship with the DF was found to be the most significant as the index accounts for cumulative antecedent conditions, and it is these conditions that irrigators respond to with most certainty (i.e. forecasts are a factor, but cannot wholly be relied upon). A threshold of DF $>6$ typically separates days of irrigation from days of no irrigation. This threshold was supported by the regression analysis and the fitted GAM, as well as the behaviour of the DF index itself. A DF of 6 represents a roughly 'neutral' DF, where it is neither particularly dry nor wet. We conclude that a threshold of DF $>6$ offers a potentially useful 'ruleof-thumb' for managers of electricity supply and distribution, managers of water resources, and irrigators. It may be used to minimise the risk of electrical supply issues, improve water availability and optimise irrigation scheduling. The findings of the study support the expansion of the methodologies to the rest of Tasmania, and potentially Australia, along with the replacement of the DF with a new irrigation index. 


\section{Acknowledgements}

This study was supported by a Dean's Summer Research Scholarship from the Faculty of Science, Engineering and Technology at the University of Tasmania. The authors wish to acknowledge the generous support of Paul Fox-Hughes, Bureau of Meteorology, Mike O'Shea, Tasmanian Irrigation, and Chong Ong, TasNetworks, for the provision of data and comments during the preparation of the manuscript. 


\section{References}

Addink J, Addink S (2003) Agricultural irrigation schedules based on evapotranspiration. WIPO 2003081362:A1. World Patent, filed March 21, 2002, and issued October 2, 2003

Alfaro EJ, Pierce DW, Steinemann AC, Gershunov A (2005) Relationships between the Irrigation-Pumping Electrical Loads and the Local Climate in Climate Division 9, Idaho. J Appl Meteorol 44 (12): 1972-78

Allen RG, Pereira LS, Raes D, Smith M (1998) Crop evapotranspiration: guidelines for computing crop water requirements. Irrigation and drainage Paper No. 56, food and agricultural organization of the United Nations (FAO), Rome, Italy

Bartos MD, Chester MV (2015) Impacts of climate change on electric power supply in the Western United States. Nat Clim Change 5: 748-752. doi:10.1038/nclimate2648

Bos MG, Kselik RAL, Allen RA, Molden D (2009) Water Requirements for Irrigation and the Environment. Springer, New York CSIRO (2009) Water Availability for Tasmania. Report to the Australian Government from the CSIRO Tasmania Sustainable Yields Project. CSIRO Water for a Healthy Country Flagship, Australia. doi: 10.4225/08/58557f4317516

Döll P (2002) Impact of climate change and variability on irrigation requirements: a global perspective. Climatic Change 54 (3): 269-93

Doulgeris C, Georgiou P, Papadimos D, Papamichail D (2015) Water allocation under deficit irrigation using MIKE BASIN model for the mitigation of climate change. Irrig Sci 33: 469. doi:10.1007/s00271-015-0482-4

Dubus L (2010) Practices, needs and impediments in the use of weather/climate information in the electricity sector. Management of Weather and Climate Risk in the Energy Industry. NATO Science for Peace and Security Series C: Environmental Security. Springer, Dordrecht

Evans R, Sneed R, Hunt JH (1996) Irrigation Management Strategies to Improve Water and Energy Use Efficiencies. North Carolina Cooperative Extension Service, Raleigh, NC, USA

FAO (2017) AQUASTAT - FAO's Information System on Water and Agriculture. Food and Agriculture Organization of the United Nations.

http://www.fao.org/nr/water/aquastat/didyouknow/index3.stm. Accessed 15 February 2017

Fernández García I, Montesinos P, Camacho Poyato E, Rodríguez Díaz A (2016) Energy cost optimization in pressurized irrigation networks. Irrig Sci 34: 1-13 
Finkele K, Mills GA, Beard G, Jones DA (2005 rev 2006) National Gridded Drought Factors and Comparison of Two Soil Moisture Deficit Formulations Used in Prediction of Forest Fire Danger Index in Australia. Aust Meteorol Mag 55: 183-197

García-Tejero IF, Durán-Zuazo VH, Muriel-Fernández JL, Rodríguez-Pleguezuelo CR (2011) Water and Sustainable Agriculture. Springer, New York

Gellings CW (2009) Energy Efficiency in Pumping and Irrigation Systems. Efficient Use and Conservation of Energy Vol. 2. Eolss Publishers, Paris, France

Georgiou PE, Papamichail DM (2008) Optimization model of an irrigation reservoir for water allocation and crop planning under various weather conditions. Irrig Sci 26: 487-504. doi:10.1007/s00271-008-0110-7

Gleick PH (2003) Water Use. Annual Review of Environment and Resources. http://annualreviews.org/doi/full/10.1146/annurev.energy.28.040202.122849. Accessed 15 March 2017

Griffiths D (1999) Improved Formula for the Drought Factor in McArthur's Forest Fire Danger Meter. Aust Forestry 62 (2): 202-6

Grolemund G, Wickham H (2011) Dates and Times Made Easy with Lubridate. J Stat Softw 40(3): $1-25$

Grose MR, Barnes-Keoghan I, Corney SP, White CJ, Holz GK, Bennett JB, Gaynor SM, Bindoff NL (2010) Climate Futures for Tasmania: general climate impacts technical report. Antarctic Climate \& Ecosystems Cooperative Research Centre, Hobart, Australia

Guerra LC, Hoogenboom G, Hook, Thomas DL, Boken VK, Harrison KA (2005) Evaluation of on-farm irrigation applications using the simulation model EPIC. Irrig Sci 23: 171-181. doi:10.1007/s00271-005-0105-6

Henningsen A, Toomet O (2013) miscTools: Miscellaneous Tools and Utilities. R Package Version 0.6-16. https://CRAN.R-project.org/package=miscTools. Accessed 16 February 2017

Leenhardt D, Trouvat J-L, Gonzalès G, Pérarnaud V, Prats S, Bergez, J-E. (2004a) Estimating irrigation demand for water management on a regional scale: I. ADEAUMIS, a simulation platform based on bio-decisional modelling and spatial information. Agr Water Manag 68: 207232. doi:10.1016/j.agwat.2004.04.004

Leenhardt D, Trouvat J-L, Gonzalès G, Pérarnaud V, Prats S, Bergez, J-E. (2004b) Estimating irrigation demand for water management on a regional scale: II. Validation of ADEAUMIS. Agr Water Manag 68: 233-250. doi:10.1016/j.agwat.2004.04.003 
Meander Valley Council (2013) Importance of Agriculture. Meander Valley Council, Deloraine, Australia

Mount AB (1972) The Derivation and Testing of a Soil Dryness Index: Using Run-off Data. Forestry Commission of Tasmania, Hobart, Australia

NPSI (2012) Irrigation Essentials Updated.

http://www.insidecotton.com/xmlui/bitstream/handle/1/1954/npsi06121-irrigation-essentialsupdated.pdf?sequence=3\&isAllowed=y. Accessed 26 February 2017

Peck DE, Peterson JM (2013) Introduction to the special issue on 'Climate Variability and Water-Dependent Sectors: Impacts and Potential Adaptations'. J Nat Resour Rolicy Res 5 (2-3): 73-77

RStudio Team (2015) RStudio: Integrated Development for R. RStudio. http://www.rstudio.com/. Accessed 16 February 2017

R Team (2017) R: The R Project for Statistical Computing. http://www.R-project.org. Accessed 16 February 2017

Roth G (2012) Irrigation in Australia Facts and Figures.

http://www.nswic.org.au/pdf/irrigation_statistics/Facts\%20Figures.pdf. Accessed 16 February 2017

Schiermeier Q (2015) Quest for Climate-Proof Farms. Nature 523 (7561): 396

Shorten P, Rostron L, Eyre D, Flores G (2014) Electricity or Diesel for Irrigation Pumping the Key Energy Consideration at a Mixed-Farm Enterprise. Farm Energy Innovation Program (EEIG), New South Wales, Australia

Stark GL, Stetson LE (1985) Comparison of Farmstead, Irrigation, and Residential Demands on Rural Feeders in Central Nebraska. T Am Soc Ag Eng 28 (5): 1657-63

Stetson LE, Addink JW (1977) Controlling Peak Electrical Demands by Scheduling Irrigation Systems. T Am Soc Ag Eng 20(4): 0754-57

Stocker TF, Qin D, Plattner GK, Tignor M, Allen SK, Boschung J, Nauels A, Xia Y, Bex V, and Midgley PM (2013) IPCC: Summary for Policymakers. In: Climate Change 2013: The Physical Science Basis. Cambridge University Press, Cambridge, United Kingdom and New York, NY, USA

TasNetworks (2015) TasNetworks Corporate Plan. Tasmanian Networks Pty Ltd, Hobart, Australia 
Tuszynski J (2014) caTools: Tools: Moving Window Statistics, GIF, Base64, ROC AUC, Etc.. R Package Version 1.17.1. https://CRAN.R-project.org/package=caTools. Accessed 5 June 2016

Wickham H (2016) Readxl: Read Excel Files. R Package Version 0.1.1. https://CRAN.Rproject.org/package=readxl. Accessed 10 April 2016

Wickham H, Romain F (2016) Dplyr: A Grammar of Data Manipulation. R Package Version 0.5.0. https://CRAN.R-project.org/package=dplyr. Accessed 18 January 2017

Wood SN (2006) Generalized Additive Models: An Introduction with R. Vol. 66. CRC Press. Boca Raton, FL, USA

Wood SN (2011) Fast stable restricted maximum likelihood and marginal likelihood estimation of semiparametric generalized linear models. J Roy Stat Soc B 73: 3-36. doi:10.1111/j.14679868.2010.00749.x 


\section{Figure captions}

Fig. 1 Location of the Greater Meander Irrigation Scheme (GMIS) in northern Tasmania, Australia.

Fig. 2 Comparison of time series from the Meander region of Tasmania (2004-2016): a) Electrical Load, b) Irrigation Load, c) Drought Factor, d) Soil Dryness Index, e) Daily Rainfall, and f) Daily Maximum Temperature. The 2010/11 and 2012/13 irrigation seasons are highlighted (grey shading), representing a cool/wet season and a hot/dry season respectively.

Fig. 3 Comparison of Soil Dryness Index (SDI) and Irrigation Load. Each colour represents a growing year (July to June).

Fig. 4 Comparison of Drought Factor (DF) and Irrigation Load. Each colour represents a growing year (July to June).

Fig. 5 GAM fits of Irrigation Load vs. Drought Factor (DF), shown as a difference from the mean load. Grey shading represents the $95 \%$ confidence interval.

Fig. 6 Irrigation load compared to Drought Factor (DF) for all data, separated by 'growing year' . The black line is the mean of all irrigation seasons post 2007.

Fig. 7 Irrigation load compared to Drought Factor (DF) and rainfall for each of the irrigation seasons 2004-2015. The irrigation load (green line) is normalised to the maximum load of that growing year. The DF (brown line) is normalised to 10. Rainfall (blue points) are binned and normalised to the max-bin (bins: 0, 0-2, 2-3.5, 3.5-5.5, 5.5-9, 9-15.5 and 15.5+ mm, representing 0-75, 75-80, 80-85, 90-95, 95-100 percentiles). 


\section{Greater Meander Irrigation Scheme}

Fig. 1 Location of the Greater Meander Irrigation Scheme (GMIS) in northern Tasmania, Australia. $74 \times 70 \mathrm{~mm}(300 \times 300 \mathrm{DPI})$ 


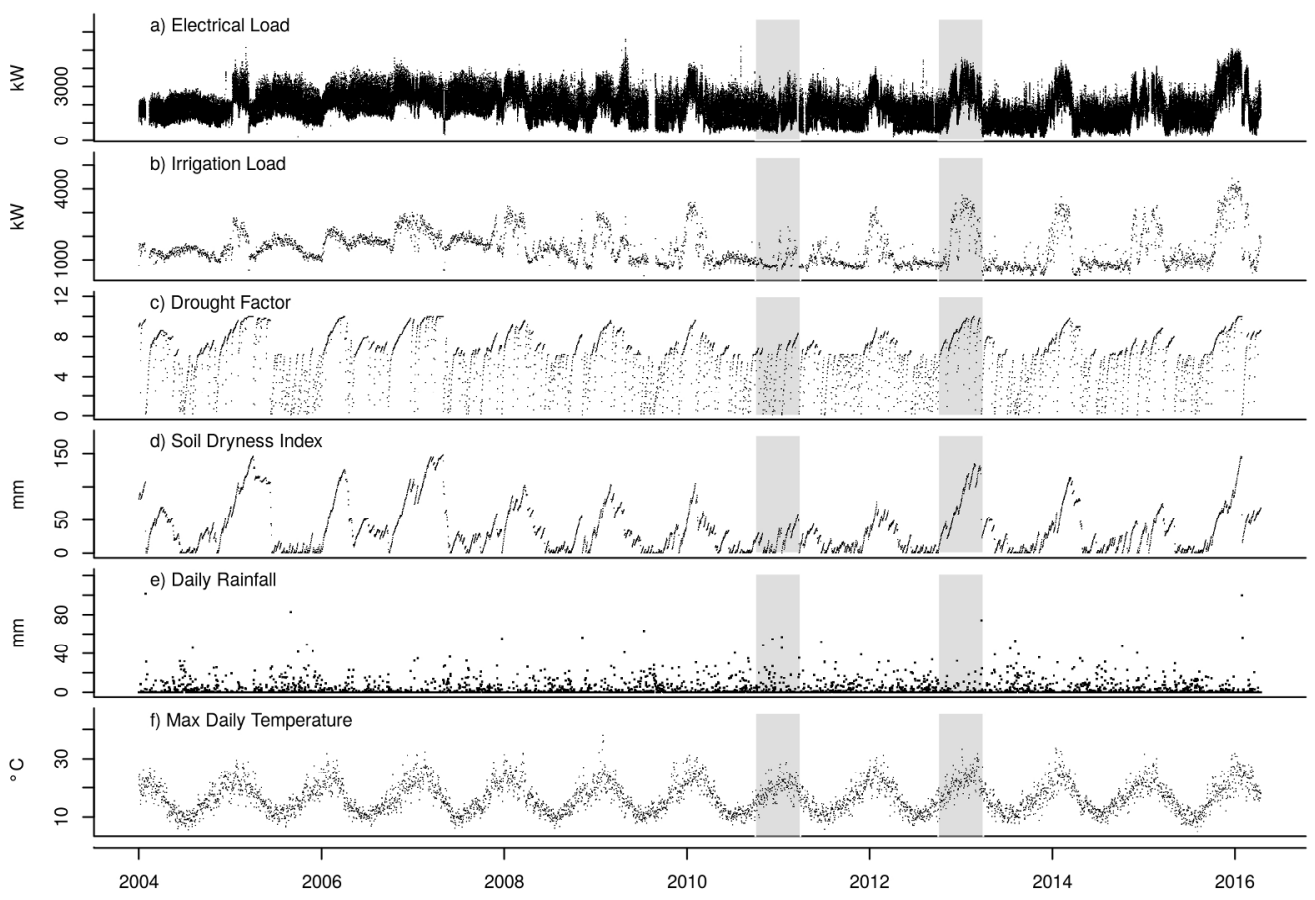

Fig. 2 Comparison of time series from the Meander region of Tasmania (2004-2016): a) Electrical Load, b) Irrigation Load, c) Drought Factor, d) Soil Dryness Index, e) Daily Rainfall, and f) Daily Maximum Temperature. The 2010/11 and 2012/13 irrigation seasons are highlighted (grey shading), representing a $\mathrm{cool} /$ wet season and a hot/dry season respectively.

$198 \times 135 \mathrm{~mm}(300 \times 300 \mathrm{DPI})$ 

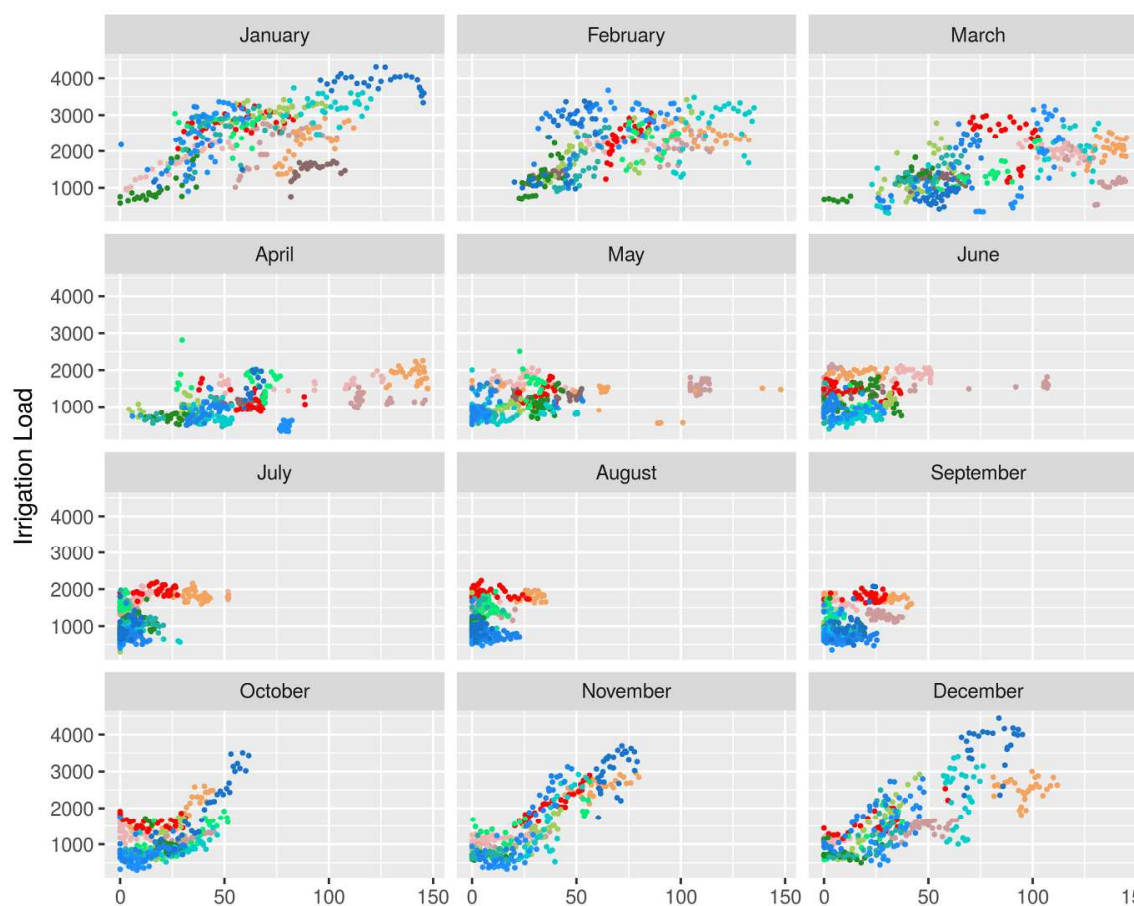

Growing
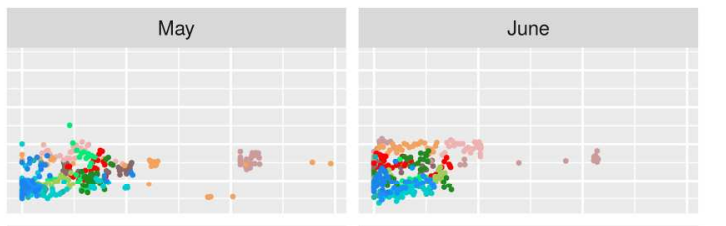

- 2003

- 2004

2005
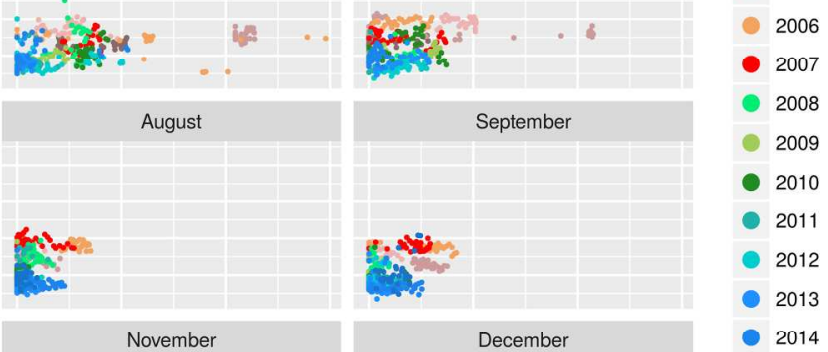

2008

2009

- 2010

- 2011

- 2012

- 2013
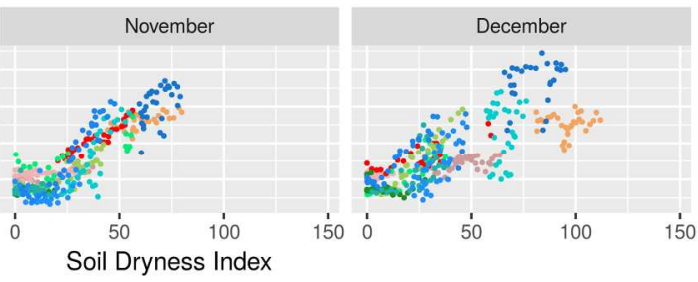

- 2014

- 2015

Fig. 3 Comparison of Soil Dryness Index (SDI) and Irrigation Load. Each colour represents a growing year (July to June).

$203 \times 148 \mathrm{~mm}(300 \times 300 \mathrm{DPI})$ 


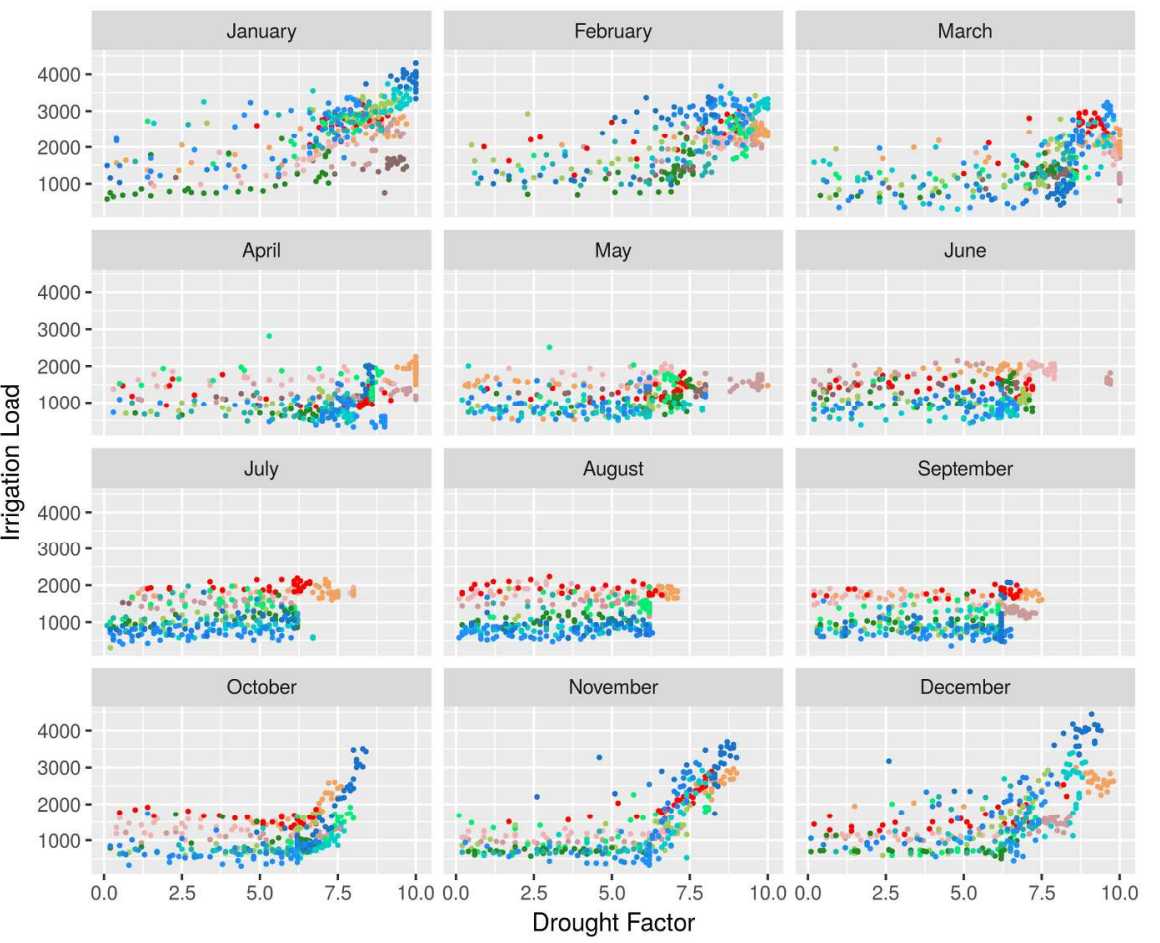

Growing

Year

- 2003

- 2004

(1) 2005

2006

- 2007

- 2008

- 2009

- 2010

- 2011

- 2012

- 2013

- 2014

- 2015

Fig. 4 Comparison of Drought Factor (DF) and Irrigation Load. Each colour represents a growing year (July to June).

$203 \times 148 \mathrm{~mm}(300 \times 300 \mathrm{DPI})$ 
Fig. 5 GAM fits of Irrigation Load vs. Drought Factor (DF), shown as a difference from the mean load. Grey shading represents the $95 \%$ confidence interval.

$297 \times 203 \mathrm{~mm}(250 \times 250 \mathrm{DPI})$ 


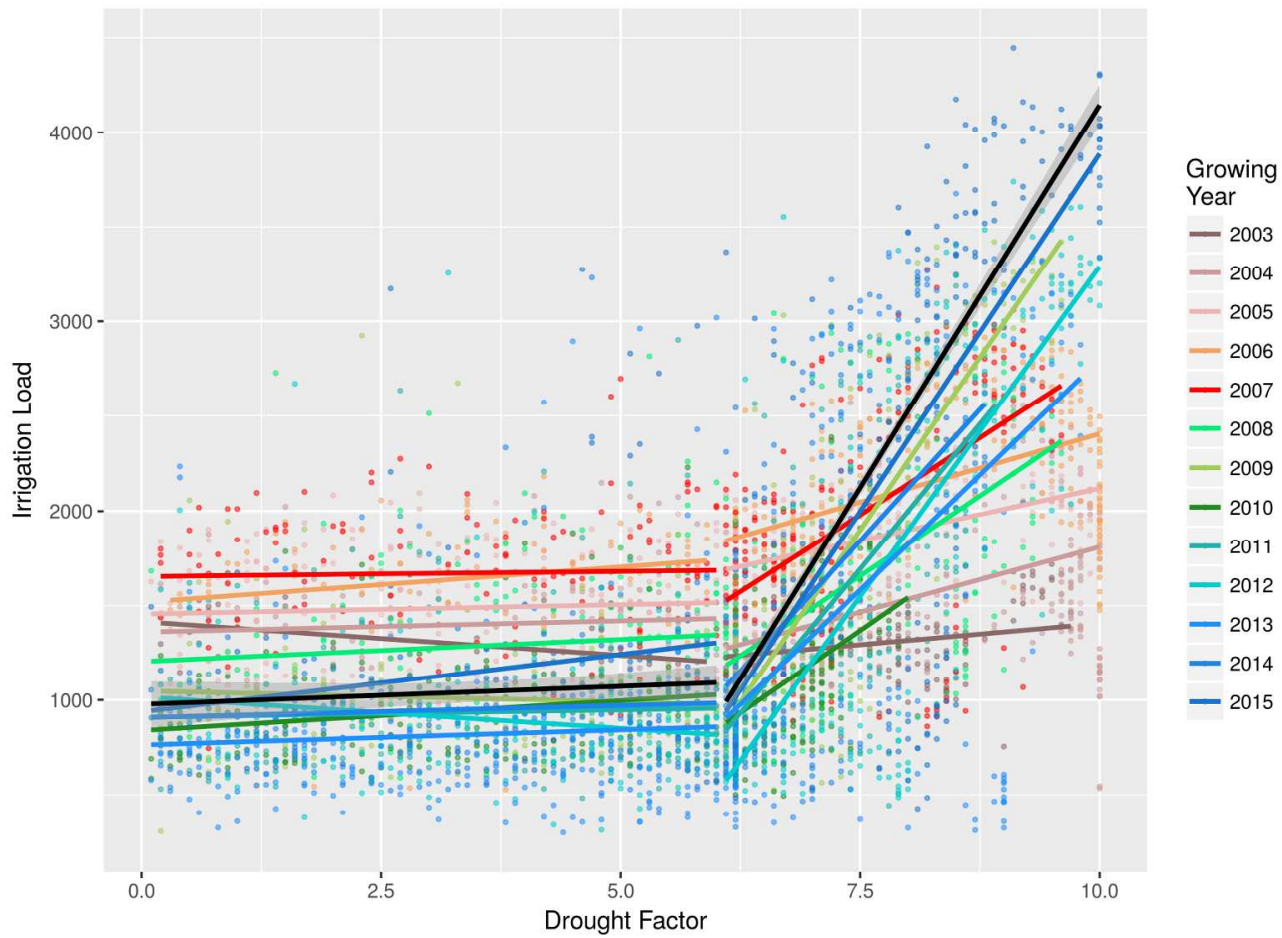

Fig. 6 Irrigation load compared to Drought Factor (DF) for all data, separated by 'growing year'. The black line is the mean of all irrigation seasons post 2007.

$203 \times 148 \mathrm{~mm}(300 \times 300$ DPI $)$ 


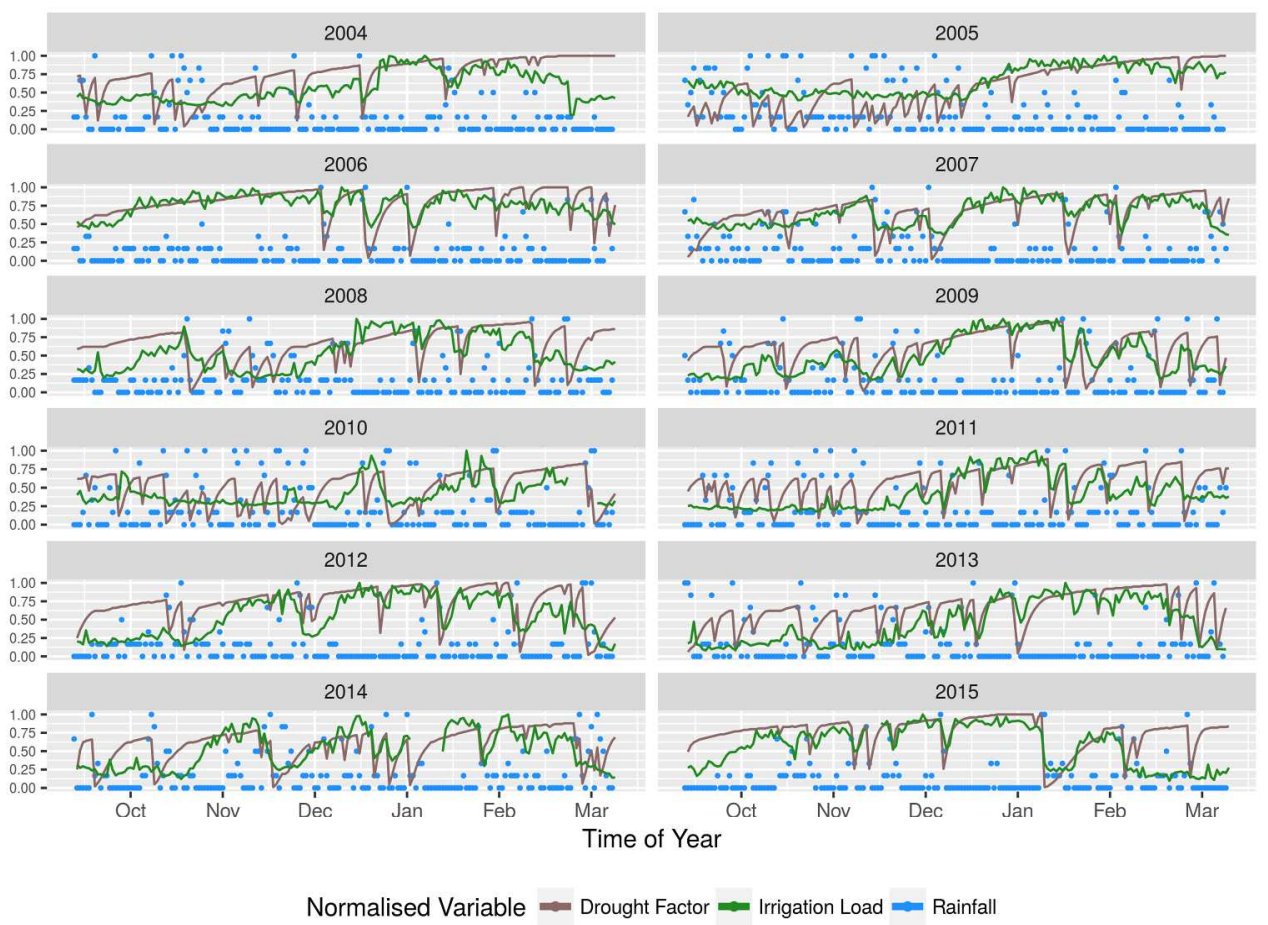

Fig. 7 Irrigation load compared to Drought Factor (DF) and rainfall for each of the irrigation seasons 20042015. The irrigation load (green line) is normalised to the maximum load of that growing year. The DF (brown line) is normalised to 10. Rainfall (blue points) are binned and normalised to the max-bin (bins: 0 , $0-2$, 2-3.5, 3.5-5.5, 5.5-9, 9-15.5 and 15.5+ mm, representing 0-75, 75-80, 80-85, 90-95, 95-100 percentiles).

$203 \times 148 \mathrm{~mm}(300 \times 300$ DPI $)$ 